\title{
Chapter 11 \\ Skills Training and Workforce Development with Reference to Underemployment and Migration
}

\author{
Brajesh Panth
}

\section{South Asian Context}

Asia 2050 (Asian Development Bank 2011) presents two scenarios: (1) the Asian Century with a sustained high economic growth leading to doubling of Asia's share of global GDP from around $25 \%$ currently to just over $50 \%$ by 2050 and (2) the "middle-income trap" for several countries, leading to much lower growth and GDP. To sustain growth and realize the Asian Century, Asia needs to match its investments in infrastructure with commensurate investments in human capital to sustain inclusive growth (high-quality education, innovation, and knowledge management), reduce rising inequality amidst rapid economic growth, and innovate to increase productivity to move up the value chain to avoid the "middle-income trap." Of the countries expected to be at the forefront of growth as per Asia 2050, India in South Asia is expected to be one of the leaders to achieve a sustained high economic growth rate. Other countries are expected to be on a slower trajectory, but they have high potential if they are able to undertake and sustain major reforms. All these countries have to overcome increasing inequality within countries, rising income disparities across countries, intense competition for finite resources, global and climate change, and poor governance and weak institutional capacity.

South Asia is one of the fastest growing and dynamic regions in the world. Its population is also one of the youngest in the world, with $40 \%$ of the population below the age of 20 . The population is expected to grow for the next three decades before stabilizing. With significant increase in labor mobility and the young labor

\footnotetext{
B. Panth $(\bowtie)$

South Asia Department, Asian Development Bank, 1550 Mandaluyong,

Metro Manila, Philippines

e-mail: bpanth@adb.org
} 
force expected to increase by more than 350 million people or $40 \%$ of the increase in the global labor force in the next two to three decades (World Bank 2011b), South Asia has a major window of opportunity to tap "demographic dividends" to become a major supplier of the global labor force, at least in the short to medium term. The dual challenge of South Asia is to create more quality jobs and concurrently improve productivity of the labor force to move up the value chain to avoid falling into the "middle-income trap." ${ }^{\prime 1}$ Not living up to this challenge risks turning the demographic dividends into a curse. Two concurrent strategies are therefore vital for South Asia: (1) enhancing skills of its overseas labor to double or triple remittances in the shorter term and (2) invest strategically in education and training to prepare high-quality labor to sustain higher economic growth including expanding labor market opportunities to absorb the growing labor force in the domestic market in the longer term. Ensuring this balance will serve as a tipping point for South Asia.

\section{Human Development in South Asia}

Compared to other regions of the world, South Asia's performance in human development is only slightly better than that of sub-Saharan Africa and has continued to lag behind other regions by a wide margin (see Table 11.1). While the average years of schooling in South Asia have improved in the past five decades, ${ }^{2}$ with primary education almost reaching the global average, secondary education lags behind significantly, except for Sri Lanka (with over 10 years of average schooling), which is far ahead of the South Asian average due to its sustained investment in the education sector since the 1940s. South Asia was able to increase the mean years of schooling of its population from 2.9 years to 5.6 between 1980 and 2005 compared to sub-Saharan Africa's achievement of 2.8-5.5. However, South Asia lags behind significantly compared to the corresponding mean years of schooling of 8.3 and 8.4 for East Asia and Latin America in 2010, respectively, and 10.6 years for the advanced countries (International Labour Organization 2012). In other words, although South Asia has been able to catch up in terms of primary education, it needs to step up its efforts to do the same at the secondary level, with substantial improvements in quality, relevance, and functional skills.

Currently, the gross enrollment rate for secondary education is less than $60 \%$ and for higher education less than $15 \%$, compared to over $90 \%$ and over $30 \%$, respectively, for most of the other regions. Although rising, the human development

\footnotetext{
${ }^{1}$ McKinsey Quarterly (2011). Why US productivity can grow without killing jobs. The report shows how the United States was able to realize productivity gains continuously over the past 80 years, largely due to its sustained investments in skills and infrastructure, and the associated gains in knowledge, technology, and innovation. More recently productivity gains have been associated with efficiency.

${ }^{2}$ Barro and Lee (2010). The study shows robust evidence of a positive association between changes in education and economic growth. However, it also shows a persistent gap in the achievement of students in developed and developing countries over time.
} 
Table 11.1 Human development indicators (latest)

\begin{tabular}{lccccc}
\hline Indicators & Bangladesh & India & Nepal & Pakistan & Sri Lanka \\
\hline Population (million) & 148.7 & $1,170.9$ & 29.96 & 173.6 & 20.9 \\
Population growth rate & 1.12 & 1.34 & 1.77 & 1.80 & 0.92 \\
Adult literacy rate & 55.9 & 65.0 & 59.1 & 55.5 & 90.6 \\
Average years of schooling & 6.19 & 5.74 & 4.68 & 5.0 & 10.43 \\
Secondary GER & 49.29 & 60.16 & 43.50 & 34.23 & 87.07 \\
Tertiary GER & 10.59 & 16.23 & 5.56 & 5.36 & 12.0 \\
Life expectancy & 68.9 & 66.33 & 68.77 & 65.85 & 77.73 \\
Human Development Index & 0.500 & 0.547 & 0.458 & 0.504 & 0.691 \\
HDI rank & 4 & 2 & 5 & 3 & 1 \\
\hline
\end{tabular}

Source: World Bank and ADB databases, various years (Data for available latest years) GER gross enrollment rate, HDI Human Development Index

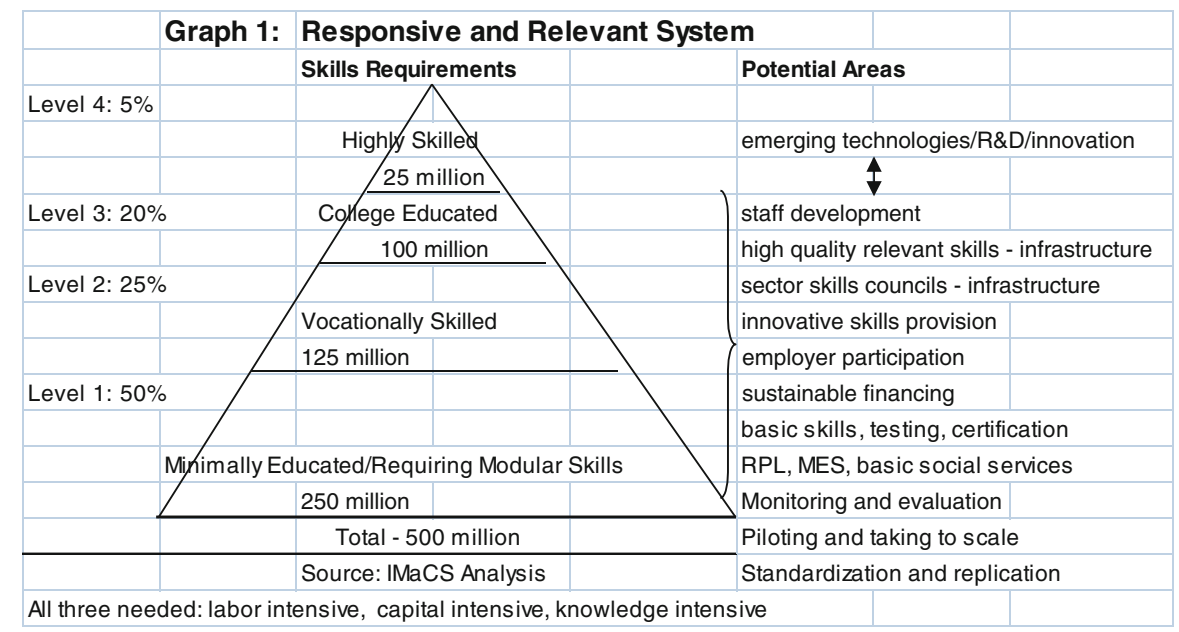

Graph. 11.1 Responsive and Relevant System (MES modular employable skills, $R P L$ recognition of prior learning)

index in South Asia is still quite low, with the exception of Sri Lanka. Successful countries focus on basic schooling as a foundation for developing a solid skill base of their population. For example, the Republic of Korea and more recently the People's Republic of China (PRC) have demonstrated how almost universal completion of basic education (9 years or more) provides the foundation to build on needed soft skills. India is now moving in this direction with its policy to achieve universal access to secondary education by 2017. Sri Lanka has already achieved an average schooling of over 10 years compared to less than 6 years in South Asia. Other South Asian countries are also moving in this direction with priority programs.

Graph 11.1 provides the overall needs for skills development in India. Although each country in South Asia is different, this framework is useful to analyze more broadly the situation in all countries. It illustrates how crucial it is for South Asia to significantly enhance its average educational attainment and skills of high quality to move up the value chain and not succumb to the "middle-income trap." 
Due to uneven quality of education, the soft skills (team work, analytical skills, critical thinking, communication, problem solving) required for the world of work remain inadequate among graduates of formal schooling. This is also true at higher levels of education, including technical/engineering higher education. As a result, the soft skills that the formal education system has failed to develop among its graduates are putting pressure on skills development system to compensate, which is unrealistic. Moreover, linking skills training to the failure of formal education will only exacerbate and protract the situation since this reinforces the perception that only those who fail formal schooling seek skills training, a social stigma that is difficult to undo. Therefore, when arguing for enhancing skills of the population in general and the workforce in particular, the South Asian countries have to view the entire education system in totality in order to make a balanced investment in education and training to optimize synergies needed between formal education and skills training. This chapter emphasizes the need to invest in lifelong learning to create such synergies as a longterm strategy across the education sector to systematically address skills development and employability to move to a trajectory of sustained high economic growth.

\section{Global Labor Market Situation}

McKinsey's latest report-The World at Work: Jobs, pay and skills for 3.5 billion people-provides the following important findings that have major implications on South Asia (McKinsey and Company Global Institute 2012): (1) 1.1 billion nonfarm jobs have been created in the past decade, of which $80 \%$ are in developing economies; (2) 245 million college graduates have entered the labor force; (3) foreign-borne workers accounted for $40 \%$ of the total labor force growth; (4) 1 in 5 nonfarm job was associated with exports; (5) there were 75 million unemployed youth in the 15-24 age group; (6) the global labor force is expected to grow from 2.9 billion today to 3.5 billion by 2030 ; (7) it is estimated that there will be a potential shortage of 38-40 million college graduates in the labor force by 2020; (8) South Asia and Africa will account for $60 \%$ of the labor force growth; and (9) there will be an additional 360 million older people that will not be part of the labor force. It also notes that the "great recession" has pushed more people to longterm unemployment and youth unemployment has reached crisis proportions. The report cautions that there will be a surplus of 90-95 million (13\% of demand) lowskills jobs and a shortage of around 45 million mid-skill jobs (15\% of demand) in developing countries. A major implication is that without aggressive investment in education and training, millions of people may be trapped in the subsistence agricultural jobs, and the economies will see slower productivity gains.

\section{Labor Market Situation in South Asia}

The labor force participation rate in South Asia was around 57.1\% (81.4\% for males and $31.7 \%$ for females) in 2010, ranging from 54\% in Pakistan and Sri Lanka to over $70 \%$ in Bangladesh and Nepal. Due to relatively low participation rate of 
Table 11.2 Labor market indicators

\begin{tabular}{llllll}
\hline Indicators & Bangladesh & India & Nepal & Pakistan & Sri Lanka \\
\hline Percent of youth population (15-35 years) & 37.81 & 35.1 & 35.94 & 35.0 & 34.23 \\
Labor force participation rate & 70.7 & 57.6 & 71.5 & 54.3 & 54.2 \\
Labor force growth rate & & & & 2.7 & 0.5 \\
Annual new labor market entrants (million) & 1.5 & 12.5 & 0.45 & 1.2 & 0.30 \\
Unemployment rate & 4.3 & 4.4 & 2.8 & 5.0 & 4.9 \\
Youth unemployment rate & 9.0 & 11.0 & 8.8 & 8.0 & 21.0 \\
Share of informal labor force & 85 & 82.8 & 71.6 & 63.1 & 39.8 \\
Dependency ratio & 54.7 & 56.3 & 68.3 & 69.4 & 46.5 \\
\hline
\end{tabular}

Source: World Bank, International Labour Organization, various years (latest)

women, the overall labor force participation is lower compared to other regions. While the overall unemployment rate is relatively low at less than $5 \%$, the youth unemployment rate is much higher at over $10 \%$ (21\% in Sri Lanka). Given that South Asia accounts for $27 \%$ of the world youth population, this continues to pose a major source of disenchantment and potential threat to peace and stability in the region. The low average unemployment rate grossly masks a very high underemployment rate, which is estimated at over $30 \%$. Every year over 16 million people enter the labor force in South Asia, which is the highest in the world. However, the employment growth rate has declined from around 2.5\% during 2001-2006 to around $0.7 \%$ in 2010, partly reflecting the slowing down of the economic growth rate. Around half of the working poor live in South Asia. The vulnerable employment rate of $81.8 \%$ in 1991 declined to only $77.7 \%$ in 2011 (83.8\% for women and $75.5 \%$ for men) (Table 11.2)

Over $70 \%$ of the labor force is engaged in informal or unorganized labor in South Asia. Much of this is stuck in the agricultural sector, which will need to transform in order to have a major dent on informal employment.

In line with the global trend, the contribution of agriculture to GDP is gradually declining, ranging from agriculture's share of GDP from $12.8 \%$ in Sri Lanka to $34.9 \%$ in Nepal. While the share of the services sector is generally quite high (over $50 \%$ ), the share of manufacturing has increased only marginally (around 20\%). Despite the declining share of agriculture, the share of employment in agriculture is still very high in South Asia, ranging from over 30\% in Sri Lanka to over 50\% in India and Nepal. Interestingly, even the PRC, which has been highly successful in transitioning from largely an agrarian economy about 30 years ago to a robust economy with the share of manufacturing and services sector at over $40 \%$ of GDP, the employment share in agriculture is over $30 \%$, similar to what is observed in South Asia. Thus, the sticky nature of agriculture's share of labor remains a major challenge for South Asia (and other regions); this is where a major dent is needed by creating jobs at this level to crack informal and/or unorganized labor including increasing productivity. This is not limited to labor market issues, but also requires technological solutions as well as land management, combined with targeted education and training to enhance the overall productivity of agriculture (Table 11.3). 
Table 11.3 Economic structure-share of GDP and employment

\begin{tabular}{|c|c|c|c|c|c|c|c|c|c|c|}
\hline \multirow[b]{2}{*}{ Economic Structure } & \multicolumn{2}{|c|}{ Bangladesh } & \multicolumn{2}{|l|}{ India } & \multicolumn{2}{|l|}{ Nepal } & \multicolumn{2}{|c|}{ Pakistan } & \multicolumn{2}{|c|}{ Sri Lanka } \\
\hline & $2000^{\mathrm{a}}$ & $2010^{\mathrm{b}}$ & $2000^{\mathrm{a}}$ & $2010^{\mathrm{b}}$ & $2000^{\mathrm{a}}$ & $2010^{\mathrm{b}}$ & $2000^{\mathrm{a}}$ & $2010^{\mathrm{b}}$ & $2000^{\mathrm{a}}$ & $2010^{\mathrm{b}}$ \\
\hline \multicolumn{11}{|c|}{ Share of GDP } \\
\hline Agriculture & 25.5 & 18.8 & 23.4 & 19.0 & 38.6 & 36.0 & 25.9 & 21.2 & 17.6 & 12.8 \\
\hline Industry & 25.3 & 28.5 & 26.2 & 26.3 & 9.2 & 7.6 & 23.3 & 25.4 & 29.9 & 29.4 \\
\hline Services & 49.2 & 52.6 & 50.5 & 54.7 & 52.2 & 56.5 & 33.5 & 35.2 & 52.5 & 57.8 \\
\hline \multicolumn{11}{|c|}{ Share of employment } \\
\hline Agriculture & 62.1 & 48.1 & 59.8 & 51.1 & 73.9 & 36.8 & 48.4 & 44.7 & 30.7 & 32.6 \\
\hline Industry & 10.3 & 14.5 & 16.4 & 22.0 & 6.8 & 7.6 & 18.0 & 20.1 & 25.6 & 25.1 \\
\hline Services & 23.5 & 37.4 & 24.1 & 26.5 & 19.3 & 55.5 & 33.5 & 35.1 & 38.4 & 39.6 \\
\hline
\end{tabular}

Source: World Bank, ADB, ILO databases, various years (Data closest to the corresponding years) The total for a country may not add up to 100 ; there is another category for those unsure about any one sector

adata refer to 2006 or closest to the corresponding year

b data refer to 2010 or closest to the corresponding year

\section{Skills Training System in South Asia}

All the South Asian countries have technical and vocational education and training (TVET) system, but the average share in financing and enrollment is still very low to have a meaningful dent on the economy. For example, there are around 13 million new entrants in the labor market every year in India, but the existing capacity to train is less than $25 \%$. Similarly, there are over 1.5 million new entrants in the labor market in Bangladesh and around 450,000 in Nepal, but their capacity to train is only a fraction of the need. Of the existing training capacity, much needs to be done to enhance the overall quality and responsiveness of the TVET system. The TVET system is also plagued by very high internal (low completion rates) and external (low placement rates) inefficiencies. Another challenge facing South Asian countries is that the average educational attainment of those in the labor force and those entering the labor force is very low (over 50\% of the labor force is without primary education in India and Nepal) compared to other regions, with the exception of Sri Lanka. Public spending on TVET is very low in South Asia (less than 5\% of the education budget) compared to what it needs to meet the enormous needs for training. This is further compounded by the extremely fragmented status of training, with over 15 ministries involved in skills training in most countries.

TVET programs are largely supply driven. While the private sector is producing more graduates particularly in shorter TVET courses, TVET in general is dominated by the public sector, with very limited share of enterprise-based training compared to other regions of the world. The overall impact is little known due to an absence of systematic tracer and impact studies. Ironically, unemployment among the TVET graduates remains unacceptably high, and completion rate is low. The poor results are largely due to four major factors, among others: (1) the state-led model of the early years was too inward looking and rigid, and has not improved enough to respond to the emerging labor market needs, influenced by domestic factors as well as globalization; (2) the TVET in each country is yet to establish and operationalize some of the key elements such as a reliable labor market information 
system to track employer needs and feedback, a qualification framework to establish a robust system over time to ensure quality assurance, and a limited capacity for training of trainers to sustain quality expansion; (3) the involvement of the private sector particularly in enterprise-based training is very limited including a lack of incentives for such involvement; and (4) in general the investment in human capital has been low and lopsided in South Asia which has constrained a balanced development of the education system, and resulted in a very limited development of the TVET system.

The current state of TVET system calls for urgent rethinking and some bold initiatives to revamp the TVET system to skill and/or up-skill a large number of people within a relatively short period, if these countries are to reap the benefits of the "demographic dividends." Almost all countries realize the need to enhance skills development capacity; they have also made important commitments in their national plans to systematically redress the current situation. For example, India has expressed its commitment in three major programs-Sarva Shiksha Abhiyan (universal basic education), universal secondary education, and commitment to skill/up-skill 500 million people by 2022. Sri Lanka has made a similar commitment in its development plan to provide training to a large number of its school graduates that are unable to enter the higher education system. Bangladesh recently approved a new TVET policy, and Nepal is considering one with the move to establish a skills fund through public-private participation to train a larger number of people. These changes are particularly crucial in South Asia that is facing energy crisis; rapid expansion of urban areas that require expertise for municipal services and maintaining infrastructure; shortage of skilled people in health, education, and training; and pressure to significantly raise productivity of the agriculture sector to address sustainable food security, promoting environmentally sustainable investments, and promoting innovation and technology solutions to leapfrog development.

\section{Key Challenges Facing Skills Development in South Asia}

All the countries in South Asia are keen to invest in skills development as this provides a major source of transforming the economies of these countries. Given the relatively low HDI of these countries, it is crucial to make balanced but higher investments between education and skills development. However, in order to optimize investments, South Asia needs to address the following key challenges:

Large mismatches. South Asian countries face serious problems of three types of mismatches-demand and supply, geographic, and sectoral. ${ }^{3}$ A combination

\footnotetext{
${ }^{3}$ This is largely extracted from the "India Labor Report 2009" by TeamLease and Indian Institute of Job Training, which analyzes these mismatches in India. These mismatches are similar in nature in other countries in South Asia.
} 
of a dynamic labor market information system (LMIS) along with targeted training and placements is needed to address the three mismatches effectively.

Despite the increase in average years of schooling among the youth population and more youth completing secondary and higher education, the employability of people remains difficult because education does not necessarily provide employable or vocational skills although it does contribute to soft skills. In South Asia, it is expected that there will be more people than the available jobs at the lowskills level, while there will be more jobs at the high skills level (college graduates) than those available for such jobs. This demand and supply mismatch indicates that there is a serious mismatch between the education and skills that the youth attain and what the labor market demands. In the case of Sri Lanka, the youth have attained impressive levels of education, but their unemployment rate is also quite high at around $21 \%$. On the one hand, a significant proportion or around one-third of those graduating from university migrate to other countries, a significant proportion of those who stay behind encounter joblessness in Sri Lanka. This is also true in other countries in South Asia with a less magnitude although the educational attainment is much lower.

Geographic mismatch is another serious problem plaguing the labor market in South Asia although this has a more serious impact in larger countries such as India and Pakistan. In India, the states with much higher economic growth rates have new jobs opening up, but fewer workers are available since their population size is growing more slowly. On the other hand, the states with slower economic growth rates also have higher population growth rates with fewer new jobs opening up. The lagging states have to rely on migrant workers as a short-term strategy to cope with this challenge. Again, this mismatch is quite common in other countries of South Asia that continue to rely on export of migrant workers to offset the domestic mismatch.

The third mismatch is the sectoral mismatch which has led to a mismatch between the education and skills that the labor force possesses and the growth in the key economic sectors (agriculture, manufacturing, and services). For example, although the contribution of agriculture to GDP in all the South Asian countries has continued to decline, the proportion of employment has not declined accordingly. This means, those working in agriculture have not been able to increase their productivity and are stuck with a low income. Targeting training to those stuck in the informal sector or low productivity areas will be crucial.

Low educational attainment and high inefficiency. While South Asian countries have made progress on educational attainment, the region still lags behind substantially compared to other regions. The labor force is ill prepared for higher level jobs, which limit them to low-paying jobs. A large percentage of the labor force does not have any education although this is gradually improving. A low percentage of the labor force has higher education, and only a small percentage has some form of skills training. Without a massive effort to expand the capacity to provide high-quality formal education along with high-quality market responsive skills training, the labor force will not be able to benefit from the high economic growth. The soft skills that come from formal education are crucial to 
lay the foundation for further skills training. Therefore, South Asian countries need to pursue quality improvement at all levels of education while targeting skills development for optimal return.

Large informal sector. Most of the countries in South Asia have a large informal sector, ranging from over $70 \%$ of the labor force in Bangladesh and Nepal to over $80 \%$ in India. While the contribution of the agriculture sector to GDP is declining, a large proportion of the labor force is still stuck in agriculture. This remains as one of the biggest challenges.

High youth unemployment. While youth unemployment is $2-3$ times the adult unemployment in most regions, it may be almost 4 times in South Asia. Unless this issue is addressed seriously, it will continue to risk destabilization and discontent among youths given that South Asian countries have a large proportion of youth population with growing aspirations.

Demographic transition. Clearly, with over 30\% of the population below 14 years, most South Asian countries have a very young population, which is why South Asia has a major but limited window of opportunity (demographic dividends) to tap to catch up. The dependency ratio in South Asian countries will remain low for the next three decades, providing a major competitive advantage over many advanced countries as well as some emerging countries like the PRC where the population is beginning to age fast. In the short term, this can cater to the needs of those advanced countries that will face labor shortages due to aging and decline in population growth. But, given the low education and skills base of the South Asian population, unless the countries are able to invest in education and skills of the population urgently, there is a real danger of falling in the "middleincome trap," and the demographic dividends can easily turn into a curse. South Asia can learn from the East Asian "miracle" because "East Asia invested in its populations and converted them into highly skilled human capital."

Image and mobility. TVET has had a very poor image in South Asian countries because it is generally meant for those who fail the formal system. However, with labor mobility increasing substantially due to globalization along with remittances of migrant labor becoming a major share of GDP, these countries have realized the need to provide relevant skills to its migrant labor to increase remittance income two- or threefold within a relatively short period. The shortterm focus on targeted skills training with a long-term focus on improving the quality of formal education at all levels will provide the necessary foundation for the much needed lifelong learning to enhance the human capital base of South Asian countries to sustain high economic growth.

Private sector participation. Although the majority of skills training in most of the South Asian countries is provided by the private sector, there are three interrelated problems: (a) the placement rate is not better among graduates from private training programs, (b) the private sector is not involved adequately in curriculum and policy to ensure relevance of training, and (c) the public training programs are largely of long duration and rigid, and the placement is low, leading to high cost of training. Strong policy measures and operational linkages are needed to bring together the public and private sector to improve the quality and relevance of training. 
Balance between existing and emerging jobs. Several factors will shape future jobs: (a) South Asian countries are investing heavily in infrastructure (energy, transport, and municipal services), which will require commensurate skills to maintain and utilize optimally the rapidly building infrastructure; (b) quality and coverage of education is improving fast which will lead to higher skill jobs including the use of technology solutions that will be vital for leapfrogging development; and (c) environmentally sustainable development will increasingly require focus on green jobs which will require reorienting skills accordingly. Therefore, South Asia needs to balance between existing and emerging jobs to take advantage of new opportunities. In addition, it is equally important to focus on the following areas identified by the India Labor Report 2008 that are generally relevant broadly to evolve a good employment ecosystem: (a) rural to urban migration, (b) farm to nonfarm switching, (c) movement from unorganized to organized sector, and (d) transfer from subsistence self-employment to quality-wage employment, as these are equally applicable to other South Asian countries.

\section{Skills Training: Paradoxes and Options}

Skills training can play a transformational role in South Asia given that the status of education and particularly skills is still at a low level. In order to expand the coverage and relevance of skills training and to make it highly responsive to labor market needs, it is crucial to address some important paradoxes associated with skills training:

1. Developing countries require substantial investment in establishing market responsive skill development programs to move up the value chain. However, many established TVET programs are government run and suffer from weak relevance and high inefficiency, including high dropout and failure, and poor placement rates. Options to address this constraint include providing fiscal and administrative autonomy as well as flexibility to training providers to offer relevant courses in partnership with potential employers. Rigid, central control will prove detrimental given the changing nature of the labor market.

2. The private sector is keen to seek a strong voice in policies and standard setting, but it is often reluctant to contribute substantially to skills training. National standards are being developed in all the South Asian countries, but smaller training providers are unable to access capital to meet these standards. Options to address this include provision for innovative training funds tied to stimulate demand, job placements, and private sector participation.

3. The more the TVET system targets those most in need of skills training, the more it suffers from negative perception. TVET continues to be perceived as secondclass education, leading to different types of mismatches. Options include marketing TVET as a viable option to allow horizontal and vertical mobility and lifelong learning and participation of reputed training providers to boost employability of TVET graduates as well as its image. 
4. South Asian countries are growing fast, and their economies are modernizing fast, but the majority of the labor force continues to be trapped in agriculture and informal sector. Consequently, low labor productivity continues to drag the overall productivity although it is improving.

5. It is very encouraging to see the potential of demographic transition, but most of the South Asian countries continue to face high youth unemployment. With high unemployment rates, countries face the prospect of instability. Options to address this include ensuring soft skills from better quality formal education combined with targeted, market responsive skills training in partnership with the private sector.

6. The overall participation and completion of formal education has continued to expand, but the unemployment rates of graduates from schools, skills development, and university education remain high. This situation is largely attributed to poor quality of education at all levels and lack of linkages between education, training, and employment. Options to address this include bridging the gap between formal education, training, and employment, including emphasizing career guidance. This is more feasible within a lifelong learning model.

\section{Opportunities}

Skills development is a major priority of all countries in South Asia given the potential to transform the human capital base, similar to how the export-led growth and globalization transformed some of the Southeast Asian economies. How can South Asia respond to the huge needs of skilling and/or up-skilling millions of people?

Transforming the education and training system. Countries in South Asia are growing fast, some more rapidly. Clearly, this requires skilling people to find better jobs and contribute to this transition while moving up the value chain. South Asian countries have to enhance the quality and relevance of education in close collaboration between the education and training institutions and the employers along with evolving a robust labor market information system to reduce the mismatch between demand and supply of labor and to complement generic skills with vocational skills.

Ensuring synergy between priority investments and skills development. Due to a low infrastructure base, the South Asian countries have been unable to tap their true potential. But this is changing fast, as South Asian governments are investing huge amounts in infrastructure including energy, transport, and municipal services, to accelerate economic growth rates in their countries. India alone expects to invest around $\$ 1$ trillion in infrastructure during its 12 th five-year plan period (2012-2016). Bangladesh, Nepal, Pakistan, and Sri Lanka are pursuing ambitious projects in infrastructure. However, commensurate investments in human capital are needed to optimize the returns to infrastructure investments, 
as these are not addressed systematically. South Asia is urbanizing rapidly, and by 2050 , over $50 \%$ of the population will live in cities. For a region that is witnessing demographic transition and massive migration from rural areas to urban centers, skills development must use this opportunity as one of the key drivers for skilling and equipping people.

Migrant labor and its contribution. Almost all the South Asian countries rely heavily on remittances from migrant workers, and this has continued to grow over the years as shown in Table 11.4 below. Most of the migrant workers are engaged in unskilled labor that is dangerous and difficult. Many unskilled youths seek jobs abroad amidst chronic labor shortages in their own countries.

India remains the largest recipient of remittances (doubling from $\$ 27$ billion in 2006 to $\$ 55$ billion in 2010) from its migrant workers although remittances' share in GDP is less than 3\%. While Bangladesh (around 10\% of GDP), Pakistan (around $8 \%$ ), and Sri Lanka (around 8\%) rely heavily on remittances, Nepal's dependence has increased at an alarming rate to around 25\% of GDP in 2010. Nepal is now among the top ten countries that depend on remittances as a share of GDP. The good news for Nepal is that the proportion of people living below the poverty line has decreased from around $31 \%$ in 2003/2004 to around 25\% in 2009/2010 (Central Bureau of Statistics 2011), which is largely attributed to remittance income that affects over $50 \%$ of the households spread all over the country. Other good news is that migrant labor has reduced the pressure on domestic labor market although this may lead to major structural problems later if not addressed strategically. However, the hidden costs that come with low-skills jobs that are dangerous and difficult may also be quite high; there is very little analysis available on this. Inevitably, people's search for decent income will continue, and migrant work will remain a major source in most South Asian countries for many years. What is critical is to target skills training to those people whose income can easily double or triple within a fairly short period, and such training can also significantly raise the awareness of migrant workers to guard against exploitation and risks.

Table 11.4 Trend in migrant labor and remittances in South Asia

\begin{tabular}{|c|c|c|c|c|c|c|c|c|c|c|}
\hline & \multicolumn{2}{|c|}{ Bangladesh } & \multicolumn{2}{|l|}{ India } & \multicolumn{2}{|l|}{ Nepal } & \multicolumn{2}{|c|}{ Pakistan } & \multicolumn{2}{|c|}{ Sri Lanka } \\
\hline & $2006^{\mathrm{a}}$ & $2010^{\mathrm{b}}$ & $2006^{\mathrm{a}}$ & $2010^{\mathrm{b}}$ & $2006^{\mathrm{a}}$ & $2010^{\mathrm{b}}$ & $2006^{\mathrm{a}}$ & $2010^{\mathrm{b}}$ & $2006^{\mathrm{a}}$ & $2010^{\mathrm{b}}$ \\
\hline $\begin{array}{r}\text { Remittance } \\
\text { (billion) }\end{array}$ & 6.4 & 12.2 & 27.0 & 55.0 & 1.6 & 3.5 & 3.9 & 9.4 & 2.2 & 3.6 \\
\hline Percent of GDP & 9.0 & & 2.8 & & 18.0 & & 4.0 & & 8.7 & \\
\hline $\begin{array}{l}\text { Emigration } \\
\text { (million) }\end{array}$ & 4.9 & 5.4 & 10.0 & 11.4 & 0.75 & 0.98 & 2.2 & 4.7 & 0.935 & 1.8 \\
\hline $\begin{array}{l}\text { Labor force } \\
\text { (million) }\end{array}$ & 65.0 & 75.7 & 443.0 & 447.0 & 11.0 & 11.8 & 59.0 & 54.5 & 8.5 & 8.9 \\
\hline Dependency ratio & 63.0 & 54.7 & 59.0 & 56.3 & 73.0 & 68.3 & 71.0 & 69.4 & 45.0 & 46.5 \\
\hline
\end{tabular}

Source: World Bank $(2007,2011 a)$

${ }^{a}$ Data refer to either 2006 or close to 2006

${ }^{b}$ Data refer to either 2010 or close to 2010 
Sri Lanka has already targeted in its economic plan to more than double its remittance income by skilling and/or up-skilling its migrant labor force.

By providing some basic training to migrant workers and practical experience in their own countries before they go abroad, their income potential could double or even triple in a relatively short period, while the domestic labor market could also become more efficient. Some radical changes in the approach to migrant labor could lead to (1) rapid reduction in poverty and increased demand for quality-basic services and (2) opportunities for benchmarking labor force competencies, leading to requisite improvements in labor quality and productivity.

Regional coordination. South Asia needs to promote regional cooperation in skills development and higher education in order to (1) benchmark standards and establish quality assurance mechanism; (2) promote mutual recognition to optimize the value of labor mobility; (3) provide a mutually beneficial forum for sharing regional and global good practices and innovations on areas such as quality assurance, labor market information system, certification, mutual recognition, training of trainers, and private and employer involvement to address emerging skills shortages; and (4) promote joint collaboration in research and development.

Technology solutions. With a rapid penetration of technologies such as mobile and cheaper tablets, technology solutions provide unprecedented opportunities to leapfrog in education and training. For example, unlike in traditional learning, which was limited to schools or training centers, technology now allows accessing high-quality, free-source materials wherever there is internet access for learners. Technologies also provide promising opportunities for a common learning and/or multiple skills platform. It is now possible to transform learning by targeting the learners directly. South Asia has already started pursuing this, but much more needs to be done. Technology solutions should be at the forefront.

\section{What Can South Asian Countries Learn from Each Other?}

South Asian countries can learn from each other about some of the promising developments in the region including those that may not have worked to avoid costly mistakes. India's initiative to create a for-profit market for skills development through the National Skill Development Corporation to train 150 million people by 2022 is a radical one and a potentially big game changer. This is a viable option that needs to be pursued to complement other efforts.

Bangladesh's successful program by the Underprivileged Children's Education Program on accelerated schooling up to grade 8 followed by skills training, leading to decent job placements, provides an excellent example of targeting disadvantaged groups. This is highly relevant for South Asia given its large share of informal and vulnerable working group $(77.7 \%)$. 
Nepal's success in turning its Training Institute for Technical Instruction into a regional center of excellence that is providing customized training to participants from several countries provides a good example of how training of trainers and targeted training can be developed and institutionalized.

Sri Lanka has been reasonably successful in establishing its National Vocational Qualification Framework (NVQF) in a relatively short period. It is now working hard to operationalize it effectively, which will provide important lessons for other countries in South Asia that are pursuing this. Other countries in South Asia are seeking advice from Sri Lanka to set up their own NVQFs. What is now crucial is to operationalize NVQF with the buy-ins from the private sector and employers.

\section{What Can South Asian Countries Learn from Other Regions and Countries?}

There are several good practices in skills development from selective countries around the world that are highly relevant to South Asia. The next five paragraphs highlight some good practices that are highly relevant to South Asia.

The Republic of Korea's experience in developing a world class education and training system in a relatively short duration by closely aligning with its economic and industrial policies including a rapid transition to a knowledge economy is highly relevant for South Asia. Such a policy led the Republic of Korea to rise rapidly from a poor country in the 1950 s to a promising member when it joined the OECD group in 1996. The Republic of Korea offers relevant good practices in at least four areas: (i) alignment of education and training policy with economic development and industrial policy; (ii) high school vocational education and training, with the establishment of over 20 Meister high schools; (iii) industry-university linkages including training of trainers; and (iv) reform of the junior college system and use of customized curriculum (Choi 2012).

Canada's rich experience in community colleges is another example that is being discussed in India and may soon generate interest in other countries that are struggling to make their secondary and tertiary education more relevant with closer links with the private sector and employers. Community colleges have promising prospects in South Asia as a viable option to proliferating higher education institutions that offer courses largely on humanities and social sciences but whose graduates are unable to decent jobs. If community colleges are recognized as an integral part of higher education, this would allow an effective route for upward mobility for a large percentage of high school graduates. This could also provide targeted training to college and university graduates that lack certain marketable skills.

Singapore's Workforce Development Agency provides another highly relevant example of how Singapore has been successful in transforming its workforce and raising the productivity of its workforce to meet the emerging labor market needs by effectively monitoring the labor market needs. It is crucial to identify emerging opportunities and not just limit to existing jobs. 
Given the huge reliance of South Asian countries on remittances of migrant labor, the region can learn a lot from the Philippines' experience in managing a large migrant labor force that is working in over 100 countries around the world in a wide range of skills including nursing, allied health, hospitality industry, and construction work. The Technical Education and Skills Development Authority in the Philippines has rich experience to share on how agreements are forged with relevant overseas agencies that need to import labor.

In addition, there are other countries such as Australia, United Kingdom, and Germany that could provide selective knowledge and expertise in the areas such as developing and operationalizing NVQF for mutual recognition and regional and international benchmarking and sector skills councils to complement NVQF to drive skills development primarily through the private sector, establishing a credible quality assurance and certification system that is recognized around the world through networking and diplomatic relationships, and promoting enterprise-based training which is at a very low level in South Asia.

\section{Lifelong Learning for a Dynamic Education and Training System}

Due to the relatively low human capital base of South Asia, including poor quality and high inefficiency (high dropouts, low cycle completion, low employability), it is imperative for South Asian countries to invest significantly in human capital in a strategic way. With increasing access to technology and globalization, it is now possible to gradually evolve a holistic system that is able to address the short-term and long-term needs (quality and higher skills) to sustain high economic growth. It is for this reason investing in lifelong learning is critical for South Asian countries to ensure synergies across the education sector at all levels of education along with close alignment between the education system and economic and industrial policy. This is particularly crucial to gradually raise and sustain labor productivity over a long period.

In the context of South Asia, the key principles of lifelong learning ought to be (1) ensuring that all students are able to complete high-quality basic education of 8 or 9 years to prepare students to move to higher level of education, to transition to skills training, or to transition to jobs that will lead to a decent income; (2) ensuring vertical and horizontal mobility so that students beyond basic education can move horizontally (to work or skills training) or vertically (high-level education, skills acquisition, or progression in jobs) without any dead end; (3) recognizing and providing credits to skills acquired in schools, skills training, or jobs to facilitate people's mobility; (4) explore high-quality materials from different regional and global sources to establish national occupational standards; and (5) gradual benchmarking and mutual recognition within and outside the region to take advantage of the huge global demand for labor due to declining youth population and rising dependency ratio in more advanced countries. 


\section{Conclusion and Recommendation}

The current debate and developments on skills development raise several pertinent questions that need to be analyzed carefully to ensure optimal impact of skills development:

1. What are the implications on inclusive economic and social development? As argued in this chapter, skills development is vital for accelerating and sustaining high economic growth which is also inclusive. However, it is important to rethink skills development so that the benefits are available to a large number of people, for example, doubling or tripling the income of migrant workers through targeted training that will lead to short-term and long-term benefits.

2. What is the role of the government? The role of the government is important in policy formulation, leveraging financing, quality assurance, providing labor market information, targeting training to disadvantaged groups where the private sector is unlikely to do so, and overall coordination given the fragmentation caused by the involvement of so many ministries. It is more important to engage the private sector and employers in actual delivery and developing relevant content, in developing and operationalizing the qualification framework, and in leveraging financing to mobilize more resources. Ultimately, the challenge is to provide more and better jobs.

3. How to incentivize private sector participation to stimulate demand-driven skills development? Private sector involvement is important in different areas including policy formulation, curriculum development, resource mobilization, on-the-job training, and impact analysis to scale up relevant training. By ensuring placement-linked skills development, the private sector and employers will be inevitably involved.

4. How to raise and distribute funds for skills development in ways that improve performance? There are increasing efforts to link training with job placements. With a more robust LMIS in place, South Asian countries will be able to provide better information to training providers and trainees to develop skills in response to emerging labor market needs. Similarly, those training providers that are able to demonstrate high placement records will attract more trainees; hence, they should receive more funding. The emphasis is on enhancing the demand side.

5. What are the policy directions and implications for skills development? As noted earlier, skills training should be packaged within a lifelong learning system so that soft skills come from formal education and targeted skills development are developed based on more effective LMIS and active involvement of the private sector and employers. This balanced development is critical.

Emerging consensus. Consensus is emerging around some key areas:

1. There are many routes to skills development that should be considered.

2. The TVET system must be flexible to emerging labor market needs. 
3. Incentives must be changed to stimulate enterprises and employers to do more to respond to skills needs.

4. There is a need to benchmark quality standards, ensure performance assessment, and establish a credible certification system.

5. The use of technology and open learning systems is essential to provide opportunities to target training flexibly.

6. Labor market analysis and graduate destination surveys are essential for proper direction and feedback to make continuous improvements.

Recommendations. Given the emerging critical questions and consensus noted above, developing countries, particularly those that are still at a lower level of educational attainment, need to seriously rethink how to institutionalize lifelong learning in order to ensure a balanced investment in education and training to enhance the employability of graduates. Global research and progress made by different countries confirm that quantitative growth alone will not lead to meaningful improvements in human capital. The real returns to education come from much better quality education that provides a strong foundation (literacy, numeracy, soft skills) combined with vocational skills. Such a system is feasible if combined with formal, informal, and on-the-job training including recognition of prior learning and knowledge acquired at different learning environment.

Since skills development is spread over various ministries, it is important to take a principled approach to provide funds to programs that are market oriented, regardless of public or private providers, that meet the standards that the employers have subscribed to, and that lead to employment. At the end, it is important to expand the coverage and establish the capacity to skill and/or up-skill millions in South Asia.

Thinking globally and starting locally are crucial. However, by trying to do everything, it may not be possible to transform. There are five considerations. First, pilot and scale up emerging good practices within an evolving lifelong learning model and in the local context by drawing on experiences from the country, region, and beyond to meet the huge unmet demand for high-quality education and training. This includes replicating good models and principles. For example, placementlinked skills development.

Second, develop and harness education and training as a source as well as a priority for much higher economic growth by leveraging public resources and plowing back huge and growing private expenditures on education and training.

Third, integrate and use technology strategically to leapfrog development by continuously innovating and creating synergy between process, product, and skills to move up the value chain to help countries to evolve into a knowledge economy.

Fourth, create innovative funding models to support skills development with required flexibility to fund programs that align well with the emerging priority investments (energy, transport, municipal services, green technologies) and that meet the quality assurance requirements. This will require ensuring synergy between higher education, secondary education, and skills development to ensure a balanced development in required skills at all levels.

And, fifth, create forums and partnerships to discuss and monitor these initiatives to facilitate change and broad-based support. 
Open Access This chapter is distributed under the terms of the Creative Commons Attribution Non-commercial License which permits any non-commercial use, distribution, and reproduction in any medium, provided the original author(s) and source are credited.

\section{References}

Asian Development Bank. (2011). Asia 2050: Realizing the Asian century. Manila: ADB.

Barro, R., \& Lee, J.-W. (2010). Educational attainment in the world: 1950-2010. Stanford: National Bureau of Economic Research.

Central Bureau of Statistics. (2011). Nepal living standard survey. Kathmandu: Central Bureau of Statistics.

Choi, H., \& Minwoong, J. (2012). Case Study on South Korea's Experience with Technical and Vocational Education and Its Implications for Developing Countries. Korean Institute for Industrial Economics and Trade. Seoul. Unpublished draft commissioned by ADB's South Asia Human and Social Development Division.

International Labour Organization. (2012). The youth employment crisis: Time for action. Geneva: ILO.

McKinsey and Company Global Institute. (2012, June). The world at work: Jobs, pay and skills for 3.5 billion people.

McKinsey Quarterly. (2011, February). Why US productivity can grow without killing jobs.

TeamLease Services. (2008). India labor report 2008: The right to rise; making India's labor markets inclusive. India.

TeamLease, \& Indian Institute of Job Training. (2009). India labor report 2009.

World Bank. (2007). Migration and remittances fact book 2007. Washington, DC: World Bank.

World Bank. (2011a). Migration and remittances fact book 2011. Washington, DC: World Bank.

World Bank. (2011b). More and better jobs in South Asia. Washington, DC: World Bank. 